\title{
İkiz Açık Hipotezinin Geçerliliğinin Kırılgan Beşli Ülkeleri İçin Test Edilmesi
}

\author{
Seher BAŞ*
}

\begin{abstract}
ÖZ
Bu çalışmada, ikiz açık hipotezinin geçerliliği Kırılgan Beşli (Brezilya, Endonezya, Güney Afrika, Hindistan ve Türkiye) ülkeleri için araştırılmıştır. 2000 - 2017 dönemi için ele alınan çalışmada, panel veri analizi yöntemleri kullanılmıştır. Yüksek cari açık ve bütçe açı̆̆ına sahip kırllgan beşli ülkelerinin etkin ve sürdürülebilir bir maliye ve para politikası oluşturabilmelerinin önünde ikiz açık önemli bir sorun olabilmektedir. Çalışma kapsamında, yatay kesit bağımlılı̆̆ını dikkate alan birim kök testlerinden CADF ve SURADF testleri kullanılmıştır. Tüm ülkelerde düzeyde ve seviyede durağanlı elde edilememiştir. Bu yüzden durağan olmayan panel veri modellerinden Westerlund Hata Düzeltme Modeli tercih edilmiştir. Kısa ve uzun dönemli parametrelerin tahminlenmesinde Havuzlanmış Ortalama Grup Tahmincisi ve Birimler IÇ̧in Havuzlanmış Ortalama Grup Tahmincisi kullanılmıştır. Ampirik sonuçlara göre uzun dönemde bütçe açı̆̆ındaki \% 1 artış cari açıkta \% 0.34 oranında artışa yol açmaktadır. Bu bağlamda Geleneksel Keynesyen Yaklaşımı çerçevesinde ikiz açık hipotezinin geçerli olduğu sonucuna ulaşılmıştır.
\end{abstract}

Anahtar Kelimeler: İkiz Açık, Bütçe açı̆̆ı, Cari Açık, Durağan Olmayan Panel Veri Modelleri, Kırılgan Beşli

JEL Sinıflandirmast: $C 23$, F30, H62

\section{Testing the Validity of the Twin Deficits Hypothesis for Fragile Five Countries}

\begin{abstract}
In this study, the validity of the twin deficit hypothesis Fragile Five (Brazil, Indonesia, South Africa, India and Turkey) have been investigated for their country. Panel data methods were used in the study, which was handled for the period 2000-2017. Twin deficits can be an important problem for the fragile fives of countries with high current account deficits and budget deficits to form an effective and sustainable fiscal and monetary policy. Within the scope of the study, CADF and SURADF tests, one of the unit root tests that take into account horizontal cross-section dependency, were used. Stability at the level and level could not be achieved in all countries. Therefore, Westerlund Error Correction Model, which is one of the non-stationary panel data models, was preferred. Pooled Average Group Estimator and Pooled Average Group Estimator for Units were used to estimate short and long term parameters. According to empirical results, $1 \%$ increase in the budget deficit leads to $0.34 \%$ increase in the current account deficit in the long term. it is concluded that the twin deficits hypothesis is valid within the framework of Conventional Keynesian Theory.
\end{abstract}

Key Words: Twin Deficit, Debt deficit, Current Account Deficit, Non-Stationary Panel Data Models, Fragile Five Countries

JEL Classification: C33, F30, H62

\footnotetext{
* Araş. Gör. Seher Baş, Manisa Celal Bayar Üniversitesi, Sosyal Bilimler Enstitüsü, seher.bas@ @bu.edu.tr, ORCİD Bilgisi: 0000-0003-0974-6151 


\section{GíRiş}

Ülkelerin iç ve dış ekonomik dengesinin sağlanması makroekonomik dengesinin oluşmasında önemli rol oynar. Günümüz ekonomileri küreselleşmesinin etkisiyle söz konusu dengenin sağlanması noktasında hem cari açık hem de bütçe açığı ile karşı karşıya kalabilmektedir. Ülkelerin diğer ülkelerle yapmış oldukları mal, hizmet ve sermaye aktarımı sonucu oluşan döviz gelir/gider dengesinden kaynaklanan cari açık sermaye hareketlerinin serbestleşmesiyle birlikte özellikle gelişmekte olan ülkeler için bir sorun teşkil etmeye başlamıştır. Temelde bu ülkelerin yeterli gelir kaynaklarına sahip olmamaları nedeniyle kamu harcamalarını finansmanı noktasında sorun yaşanmaya başlaması ülke ekonomilerinde bütçe açıklarına neden olmaktadır.

İkiz açık ve ikiz açı̆̆ı belirleyen dinamikler hem gelişmiş hem de gelişmekte olan ekonomiler için önemli bir sorun teşkil etmektedir. Özellikle Türkiye gibi gelişmekte olan ülkeler açısından en öncelikli iktisadi sorunlardan başlıcası, cari açık ve bu açığın giderilmesi noktasında uygulanacak politikanın seçimidir. Söz konusu ülkelerin öncelikli olarak dış kaynak bulma sıkıntısı, teknolojik yetersizlik, ara ve yatırım mallarının ihracat gelirleriyle karşılanması bağlamında yetersiz kalınması cari açığı kronik hale getirmekte ve kalkınma sürecinde arzulanan büyüme ivmesinin yakalanmasını zorlaştırmaktadır. Öte yandan, gelişmekte olan ülkelerin cari açık finansman politikası, sorunun çözümünün mümkün olup olmadığını da ortaya koymaktadır. Nitekim cari açık, doğrudan yabancı yatırımlar yoluyla finanse ediliyorsa, cari açığın sürdürülebilirliği sağlanmış olacaktır. Bu yolla finanse edilen cari açık gelişmekte olan ülkeler için büyük bir sorun oluşturmayacaktır. Ancak cari açık, kısa vadeli spekülatif sermaye akımları şeklinde finanse ediliyorsa bu durum gelişmekte olan ülkelerde önemli bir soruna dönüşebilmektedir. Dolayısıyla cari açı̆̆ın finansman kalitesi gelişmekte olan ülkeler açısından dikkat edilmesi gereken bir husustur. Aynı şekilde bütçe açı̆̆ı, ülkelerin makroekonomik dengelerini bozabilmekte ve borçluluk düzeyini arttırabilmektedir. Diğer taraftan başta ABD olmak üzere cari açık veren gelişmiş ülkelerin istikrarı gelişmekte olan ekonomilerin gidişatı için önem arz etmektedir. ABD gibi ülkelerin paralarının rezerv para olması dolayısıyla küresel finans piyasaları hem faiz hem de döviz kurları bağlamında etkilenecektir.

Literatürde güncelliğini koruyan ikiz açık hipotezinin geçerli olup olmadığına sınamaya yönelik çok sayıda çalışma yer almaktadır. Söz konusu çalışmalarda, farklı ülkelere ait bütçe açığ 1 ve cari işlemler açığ 1 verileri, farklı ekonometrik yöntemlerle test edilmiştir. Elde edilen sonuçlar neticesinde henüz bir fikir birliği sağlanamamış olsa da, ikiz açık problemi halen birçok ekonomi için sorun olmaya devam etmektedir. Politika yapıcılar açısından bakıldığında da, hem gelir ve giderler arasında meydana gelen bütçe açığı, hem de döviz gelirleriyle döviz giderleri arasındaki açıkları gösteren cari açık önem arz etmektedir. İki açığın birlikte görülmesi ülkelerin ekonomik aktivitelerinin daha değişken ve kırılgan olmasına neden olmaktadır. Özellikle, son dönemde ekonomik zayıflıklarıyla gündeme gelen Brezilya, Endonezya, Güney Afrika, Hindistan ve Türkiye gibi kırılgan ülkeler uluslararası sermaye akımlarına bağlı olarak yüksek cari açık, bütçe 
açığg ve dış borçlulukta artış yaşamaktadır. Bu ülkelerin bir ölçüde de yükselen piyasa ekonomileri açısından benzer özelliklere sahip olduğu ve nispeten homojen sayılabilecek ülkelerden oluştuğu görülmektedir. Bu bağlamda çalışmamızda literatürde kırılgan beşli olarak kabul edilen ülkeler tercih edilmiştir.

Bu kapsamda, çalışmanın giriş bölümünde konuyla ilgili genel çerçeve ele alınmaktadır. Birinci bölümde çalışmanın kuramsal çerçevesi özetlenmektedir. İkinci bölümünde çalışma kapsamında yerli ve yabancı literatürde yer alan bazı önemli çalışmalara yer verilmiştir. Üçüncü bölümde çalışmanın veri seti, model ve yöntemi açılanmaktadır. Dördüncü bölümde ise çalışmaya konu olan Brezilya, Endonezya, Güney Afrika, Hindistan ve Türkiye gibi kırılgan kabul edilen ülkelerin ikiz açı hipotezinin birim kök testi sonuçlarıyla birlikte doğrusal olmayan verilerde kullanılan panel eşbütünleşme testleri ve kısa ve uzun dönemli tahmincilerle ampirik olarak sinanması yer almaktadır. Daha sonra ampirik bulgular özetlenmekte ve değerlendirilmektedir. Son olarak çalışmanın bulguları sonuç kısmında tartışılmıştır.

\section{KURAMSAL ÇERÇEVE}

Cari açık ve bütçe açığının birlikte görüldüğ̈̈ durumu ifade eden ikiz açık literatürde farklı kuramsal yaklaşımlar çerçevesinde ele alınmaktadır. Bu ikili arasında ilişki olup olmadığı veya arasındaki ilişkinin yönüne yönelik dört farklı yaklaşım bulunmaktadır. Bunlar; Geleneksel ya da Keynesyen Yaklaşım, Ricardocu Denklik Yaklaşımı, Parasalcı Yaklaşım ve Cari İşlemler Hedeflemesi Yaklaşımı'dır (Kim ve Kim, 2006: 676; Chan ve Hsu, 2009: 3).

Keynesyen Yaklaşım (Geleneksel) cari açık ile bütçe açı̆̆ı arasındaki ilişkinin pozitif olduğunu öne sürer. Keynesyen ikiz açık hipotezine göre bütçe açığı ile cari açık arasındaki ilişkinin yönü bütçe açığından cari işlemler açığına doğrudur. $\mathrm{Bu}$ yaklaşımda ikiz açık hipotezi Mundel-Fleming Modeli ile açıklanmaktadır (Bayrak ve Esen, 2012: 29-30; İyidoğan, 2014: 72). Buna göre yükssek sermaye akışkanlığı neticesinde oluşan cari açıkların asıl nedeni olarak bütçe açıları gösterilmektedir. Zira bu tarz ekonomilerde kamu harcamalarındaki artış veya vergi kesintileri bütçe açıklarının oluşmasına neden olacaktır. Bütçe açıkları neticesinde de ulusal faiz oranlarında artışlar meydana gelecektir. Ulusal faiz oranlarında meydana gelen bir artış ülkeye yabancı sermaye çekecek ve bu da yerli paranın değer kazanmasına neden olacaktır. Yerli paranın değer kazanması, yerli malların fiyatlarını arttırıp yabancı malların göreceli fiyatlarını azaltacağından ithalat artacaktır. Bu durum sonucunda da cari açık yükselecektir (Rosensweig ve Tallman, 1993; Erceg vd., 2005; Corsetti ve Müller, 2006).

Ricardocu Denklik yaklaşımı, bütçe açığı ile cari açık arasında herhangi bir ilişkinin olmadığını, diğer bir deyişle ikiz açık hipotezinin geçersiz olduğunu ortaya koymaktadır. Yani bu görüşe göre bütçe açığı ile cari açık arasında bir korelasyon bulunmamaktadır. Ricardocu Denklik Yaklaşımına göre kamu harcamaları sabit kalmak kaydıyla vergilerde meydana gelen bir artışın cari açık üzerinde etkisiz olacağını öne sürmektedir. Diğer bir ifadeyle bütçe açıklarının ekonominin dış cephesi üzerinde bir etkisi olmayacaktır. Zira sabit kamu harcamaları ve borçlanmada herhangi bir kısıtlamaya gidilmediği varsayımı altında, uygulanacak 
bir vergi indirimi neticesinde, ileride bir vergi artırımı ile giderileceğinden cari vergilerdeki azalma planlanan tasarruf düzeyinde bir etkiye sahip olmayacaktır. Nitekim bütçe açıkları ulusal tasarruf düzeyi ile ilişkisizdir. Aynı şekilde özel tasarruflardaki artışlar bütçe açıklarını dengeleyerek etkisiz hale getirir. Dolayısıyla bütçe açıklarının ekonomi üzerinde herhangi bir etkisi oluşmayacaktır (Barro, 1989; Garcia ve Ramajo, 2004; Uğur ve Karatay, 2009: 117).

Parasalcı (monetarist) yaklaşım ise Keynesyen Yaklaşım'a benzer bir bakış açısıyla hareket etmektedir. Buna göre, bütçe açıkları ile cari açıklar arasında pozitif yönlü bir nedensellik ilişkisi olduğunu ve bu ilişkinin de bütçe açıklarından cari işlemler açıklarına doğru olduğunu varsaymaktadır. Ancak parasalcı yaklaşımın Keynesyen Yaklaşımdan farkı, ödemeler bilançosundaki dengesizliğin, para piyasasında gerçekleşen bir dengesizlikten kaynaklandığını ve söz konusu bu dengesizliğin kendiliğinden ortadan kalabileceğini belirtmesidir (Uğur ve Karatay, 2009: 118; Kalou ve Paleologou, 2012).

Cari İslemler Hedeflemesi Yaklaşımına göre ise nedensellik ilişkisi cari açıktan bütçe açığına doğru tek yönlüdür. Literatürde bu ilişkiye ters ikiz açıklar hipotezi (reverse twin deficits hypothesis) de denmektedir. Cari İşlemler Hedeflemesi Yaklaşımına göre cari açıkta meydana gelebilecek bir kötüleşme ekonomik büyümede yavaşlamaya neden olup bütçe açığında artış meydana getirecektir. Diğer bir deyişle, diş ekonomik dengede olumsuz bir gelişme yaşanması ekonominin daralmasına sebebiyet verecek ve bu sonuç da iç ekonomik dengeyi olumsuz etkileyecektir. Bu durumun özellikle, ekonomik kalkınmasını finanse etmede yabancı sermaye girişine bağımlı olan küçük ve dışa açık gelişmekte olan ülkeler açısından geçerli olduğu görülmektedir. Kısaca, gelişmekte olan bir ülkenin yoğun sermaye girişleri ile karşılaşması ve elde edilen fonların verimli alanlarda kullanılamaması söz konusu ülkenin borçlanmasını artıracaktır. Borçların birikmesi neticesinde ise en nihayetinde ülke bütçe açı̆̆ ile karşı karşıya gelecektir (Summers, 1988; Kim ve Kim, 2006: 676; Sever ve Demir, 2007:49; Bakarr, 2014).

\section{LITERATÜR TARAMASI}

İkiz açık hipotezini farklı yaklaşımlar çerçevesinde ele alan geniş bir ampirik literatür bulunmaktadır. Cari açık ile bütçe açığı arasındaki ilişkinin varlığ konusunda tam olarak bir görüş birliği sağlanamamıştır. Söz konusu literatür ele alındığında görülecektir ki, ikili arasında herhangi bir ilişkinin olmadığını, iki yönlü bir nedensellik olduğunu veya ilişkinin yönünün cari açıktan bütçe açığına doğru olduğunu öne süren çalışmalar da bulunmaktadır. Buna göre, aşağıdaki tablo söz konusu literatürün bir özeti şeklinde sunulmuştur:

Tablo 1: İkiz Açıkla İlgili Temel Literatür İncelemesi

\begin{tabular}{|c|c|c|c|}
\hline $\begin{array}{l}\text { Yazarlar, } \\
\text { Yılı* }\end{array}$ & Ele alınan dönem, ülke(ler) ve veriler & Yöntem & Sonuç \\
\hline $\begin{array}{l}\text { Darrat } \\
(1988)\end{array}$ & $\begin{array}{c}\text { 1960: } 1 \text { - 1984:4; ABD, } \\
\text { Cari açık = CA, } \\
\text { Bütçe açığ1 = BA }\end{array}$ & $\begin{array}{c}\text { Granger } \\
\text { Nedensellik Testi }\end{array}$ & $\begin{array}{c}\text { BA } \rightarrow \text { CA } \\
\text { Bütçe açığındaki bir artış } \\
\text { cari açıkta artışa yol } \\
\text { açmaktadır. }\end{array}$ \\
\hline
\end{tabular}




\begin{tabular}{|c|c|c|c|}
\hline $\begin{array}{l}\text { Kearney ve } \\
\text { Monadjemi } \\
\quad(1990)\end{array}$ & $\begin{array}{l}\text { 1972:1-1987:4; } \\
8 \text { gelişmiş ülke } \\
\text { Cari açık = CA, } \\
\text { Bütçe açığı = BA }\end{array}$ & Var Modeli & $\begin{array}{c}\mathrm{CA} \rightarrow \mathrm{BA} \\
\text { Bütçe açığının nedeni cari } \\
\text { açıktaki artıştır. }\end{array}$ \\
\hline $\begin{array}{l}\text { Rosenweing ve } \\
\text { Tallman (1993) }\end{array}$ & $\begin{array}{c}1961-1989 ; \text { ABD; } \\
\text { Cari açık = CA, } \\
\text { Bütçe açı̆̆ } 1=\text { BA }\end{array}$ & Var Modeli & $\begin{array}{c}\mathrm{BA} \rightarrow \mathrm{CA} \\
\text { Bütçe açığındaki bir artış } \\
\text { cari açıkta artışa yol } \\
\text { açmaktadır. }\end{array}$ \\
\hline $\begin{array}{l}\text { Piersanti } \\
(2000)\end{array}$ & $\begin{array}{c}1970 \text { - 1997; } 17 \text { OECD Ülkesi, } \\
\text { Cari açık = CA, } \\
\text { Bütçe açığı = BA } \\
\end{array}$ & GMM & $\begin{array}{c}\mathrm{CA} \leftrightarrow \mathrm{BA} \\
\text { Birbiriyle ilişkilidir. }\end{array}$ \\
\hline $\begin{array}{c}\text { Garcia } \\
\text { ve } \\
\text { Ramajo, (2004) }\end{array}$ & $\begin{array}{c}1964 \text { - 2000; İspanya; } \\
\text { Bütçe açı̆̆ } 1=\text { BA, } \\
\text { Faiz oranı = İ }\end{array}$ & 2SLS Yöntemi & $\begin{array}{l}\text { BA } \neq \text { İ } \\
\text { Bütçe açı̆̆ı ile faiz oranı } \\
\text { arasında bir ilişki elde } \\
\text { edilememiştir. }\end{array}$ \\
\hline $\begin{array}{l}\text { Salvatore } \\
(2006)\end{array}$ & $\begin{array}{c}1973 \text { - 2005; G-7 Ülkeleri; } \\
\text { Cari açık = CA, } \\
\text { Bütçe açığ } 1=\text { BA }\end{array}$ & $\begin{array}{c}\text { Granger } \\
\text { Nedensellik Testi }\end{array}$ & $\begin{array}{c}\mathrm{BA} \rightarrow \mathrm{CA} \\
\text { Bütçe açığındaki bir artış } \\
\text { cari açıkta artışa yol } \\
\text { açmaktadır. }\end{array}$ \\
\hline $\begin{array}{c}\text { Acaravci ve } \\
\text { Öztürk (2008) }\end{array}$ & $\begin{array}{c}\text { 1987:1 - 2005:4; Türkiye; } \\
\text { Cari açık = CA, } \\
\text { Bütçe açı̆̆ } 1=\text { BA }\end{array}$ & ARDL, Sinır Testi & $\begin{array}{c}\text { BA } \rightarrow \text { CA } \\
\text { Bütçe açığındaki bir } \\
\text { artış cari açıkta artışa } \\
\text { yol açmaktadır. }\end{array}$ \\
\hline $\begin{array}{c}\text { Çelik ve } \\
\text { diğerleri (2008) }\end{array}$ & $\begin{array}{c}\text { 1996:1-2006:4; Türkiye,Brezilya, Çek } \\
\text { Cumh., G.Afrika Cumh. Kolombiya, } \\
\text { Meksika }\end{array}$ & $\begin{array}{l}\text { Panel Birim Kök, } \\
\text { Panel } \\
\text { Eşbütünleşme }\end{array}$ & $\begin{array}{l}\text { BA ile CA arasında bir } \\
\text { ilişki vardır. }\end{array}$ \\
\hline $\begin{array}{c}\text { Chan ve Hsu } \\
\text { (2009) }\end{array}$ & $\begin{array}{c}\text { 1980-2007; } 5 \text { Kuzey Avrupa ülkesi, } \\
4 \text { Asya ülkesi ve ABD; } \\
\text { Cari açık = CA, } \\
\text { Bütçe açı̆̆1 = BA }\end{array}$ & $\begin{array}{l}\text { Toda-Yamamoto } \\
\text { Nedensellik Testi }\end{array}$ & $\begin{array}{c}\text { CA } \rightarrow \text { BA } \\
\text { Cari açıktan bütçe açı̆̆ına } \\
\text { doğru bir nedensellik } \\
\text { vardır. }\end{array}$ \\
\hline $\begin{array}{l}\text { Çavdar } \\
(2011)\end{array}$ & $\begin{array}{c}\text { 1994:1 - 2008:4; Türkiye; } \\
\text { Cari açık/GSYH = CA, } \\
\text { Bütçe açığı/GSYH = BA }\end{array}$ & $\begin{array}{c}\text { Granger } \\
\text { Nedensellik Testi, } \\
\text { Eşbütünleşme }\end{array}$ & $\begin{array}{c}\text { CA } \rightarrow \text { BA } \\
\text { Cari açıktan bütçe açı̆̆ına } \\
\text { doğru bir nedensellik } \\
\text { vardır. }\end{array}$ \\
\hline $\begin{array}{l}\text { İyidoğan } \\
\text { (2013) }\end{array}$ & $\begin{array}{c}\text { 1987:1 - 2005:4; Türkiye; } \\
\text { Cari açık/GSYH = CA, } \\
\text { Bütçe açığı/GSYH = BA }\end{array}$ & $\begin{array}{l}\text { Toda-Yamamoto } \\
\text { Nedensellik Testi }\end{array}$ & $\begin{array}{c}\mathrm{CA} \rightarrow \mathrm{BA} \\
\text { Cari açıtan bütçe açığına } \\
\text { doğru bir nedensellik } \\
\text { vardır. } \\
\end{array}$ \\
\hline $\begin{array}{l}\text { İyidoğan ve } \\
\text { Erkam (2013) }\end{array}$ & $\begin{array}{c}\text { 1987:1 - 2005:4; Türkiye; } \\
\text { Cari açı/GSYH = CA } \\
\text { Bütçe açığı/GSYH = BA }\end{array}$ & $\begin{array}{c}\text { Granger } \\
\text { Nedensellik Testi }\end{array}$ & $\begin{array}{c}\mathrm{CA} \rightarrow \mathrm{BA} \\
\text { Cari açıktan bütçe açı̆̆ına } \\
\text { doğru bir nedensellik } \\
\text { vardır. }\end{array}$ \\
\hline $\begin{array}{l}\text { Van Bon } \\
(2014)\end{array}$ & $\begin{array}{l}1985 \text { - 2012; } 10 \text { Gelişmekte Olan Asya } \\
\text { Ülkesi; } \\
\text { Cari açık, bütçe açı̆̆ı ve diğer başka } \\
\text { değiş̧kenler }\end{array}$ & $\begin{array}{c}\text { Fark GMM } \\
\text { Dinamik Panel } \\
\text { Tahmin Yöntemi }\end{array}$ & $\mathrm{CA} \leftrightarrow \mathrm{BA}$ \\
\hline $\begin{array}{l}\text { Altunöz } \\
\text { (2014) }\end{array}$ & $\begin{array}{l}\text { 2000:1-2012:3; Türkiye; } \\
\text { Cari açık/GSYİH, Bütçe açı̆̆ı/GSYİH, } \\
\text { reel döviz kuru, devlet iç borçlanma } \\
\text { senedi verileri }\end{array}$ & $\begin{array}{l}\text { ARDL, } \\
\text { Sinır Testi }\end{array}$ & $\begin{array}{l}\text { Uzun dönemde CA } \leftrightarrow \text { BA } \\
\text { arasında bir ilişki yok.Kısa } \\
\text { dönemde CA BA } \\
\text { arasında pozitif ve güçlü } \\
\text { bir ilişki vardır. }\end{array}$ \\
\hline
\end{tabular}


Seher Baş / İkiz Açık Hipotezinin Geçerliliğinin Kırılgan Beşli Ülkeleri İçin Test Edilmesi

\begin{tabular}{|c|c|c|c|}
\hline $\begin{array}{l}\text { Özçalık ve } \\
\text { Erataş (2014) }\end{array}$ & $\begin{array}{c}\text { 1995-2010; Polonya, Yunanistan, İrlanda, } \\
\text { Portekiz, İspanya ve Türkiye; Cari } \\
\text { açık/GSYİH, Bütçe açığı/GSYİH }\end{array}$ & Panel Veri Analizi & $\begin{array}{c}\mathrm{CA} \neq \mathrm{BA} \text { arasında bir } \\
\text { ilişki yoktur. }\end{array}$ \\
\hline $\begin{array}{l}\text { Kaygisiz vd. } \\
\text { (2016) }\end{array}$ & $\begin{array}{c}\text { 2001 - 2014; Türkiye; } \\
\text { Cari açı/k/GSYH = CA } \\
\text { Bütçe açı̆̆ı/GSYH = BA } \\
\text { Reel efektif döviz kuru = REER } \\
\text { Yurt içi borçlanma faiz oranı = İ }\end{array}$ & $\begin{array}{c}\text { Toda Yamamoto } \\
\text { Testi }\end{array}$ & $\begin{aligned} \mathrm{CA} & \rightarrow \mathrm{BA}, \\
\mathrm{CA} & \leftrightarrow \dot{\mathrm{I}}, \\
\mathrm{REER} & \rightarrow \mathrm{BA}\end{aligned}$ \\
\hline $\begin{array}{c}\text { Aydin ve Afsal } \\
\text { (2018) }\end{array}$ & $\begin{array}{c}1975 \text { - 2015; Türkiye; } \\
\text { Cari açık/GSYH = CA } \\
\text { Bütçe açığı/GSYH = BA }\end{array}$ & $\begin{array}{l}\text { Toda Yamamoto } \\
\text { Nedensellik } \\
\text { Yaklaşımı }\end{array}$ & $\begin{array}{l}\mathrm{CA} \rightarrow \mathrm{BA} \\
\mathrm{BA} \rightarrow \mathrm{CA}\end{array}$ \\
\hline
\end{tabular}

*Çalışmalar yapıldığı yıla göre sıralanmıştır.

Cari açık ile bütçe açığı arasındaki ilişki literatür özetinde de görüleceği üzere farklılaşabilmektedir. Buna göre $\mathrm{BA} \rightarrow \mathrm{CA}, \mathrm{BA} \neq \mathrm{CA}, \mathrm{CA} \rightarrow \mathrm{BA}$ ve $\mathrm{BA} \leftrightarrow$ CA dahil olmak üzere bütçe açığı (BA) ile cari açık (CA) arasında dört olası ilişki kurulabilir (Chan ve Hsu, 2009: 3). Yapılan çalışmalar incelendiğinde, bütçe açığ1 ve cari açık değişkeni dışında farklı değişkenlerin de kullanıldığı ve farklı sonuçlar elde edildiği görülmektedir. Özellikle son yıllarda daha çok Türkiye ve Türkiye gibi yükselen piyasa ekonomilerinin ele alındığı görülür.

\section{VERI SETI VE EKONOMETRİK METODOLOJİ}

$\mathrm{Bu}$ kısımda ikiz açık hipotezinin geçerliliği Kırılgan Beşli (Brezilya, Endonezya, Güney Afrika, Hindistan ve Türkiye) olarak kabul edilen ülkeleri için araştıılmıştır. Bu çerçevede çalışmada 2000-2017 dönemine ait yıllık cari açık/GSYİH (CA) ve bütçe açı̆̆ı/GSYİH (BA) verileri kullanılmıştır. Dönem aralığı veri kısıtından hareketle tercih edilmiştir. Çalışmaya konu olan veri seti yüzdesel biçimde IMF Database'den derlenmiştir.

Yatay kesit bağımlılığı; Berusch-Pagan(1980) CDLM1, Pesaran vd.(2004) CDLM2, Pesaran vd.(2004) CDLM testi ve Pesaran vd. (2008) tarafindan geliştirilen sapması düzeltilmiş LMadj(Adjusted Lagrange Multiplier) testiyle incelenmiştir. Sabit ve eğim parametrelerinin homojenliği Pesaran ve Yamagata(2008) tarafından geliştirilen Swamy testi yardımıyla belirlenmiştir. Birim kökün varllğ 1 ikinci nesil birim kök testlerinden Breuer vd.(2002) SURADF (Seemingly Unrelated Regression Augmented Dickey Fuller) testi ve Pesaran(2006), CADF (Cross-sectionally Augmented Dickey Fuller) panel birim kök testleri ile araştırılmıştır. Koentegre ilişkinin tespitinde doğrusal olmayan panel veri modellerinde eşbütünleşme ilişkisini test eden Westerlund (2007) Hata Düzeltme Modeli testi tercih edilmiştir. Kısa ve uzun dönemli ilişkinin parametrelerinin tahminin de ise Pesaran, Shin ve Smith(1999) Havuzlanmış Ortalama Grup Tahmincisi (PMGE) kullanılmıştır.

\subsection{Yatay Kesit Bağımlılığı Testi}

Çalışmada yatay kesit bağımlılı̆̆1; Berusch-Pagan(1980) $\mathrm{CD}_{\mathrm{LM} 1}$, Pesaran vd.(2004) $\mathrm{CD}_{\mathrm{LM} 2}$, Pesaran vd.(2004) $\mathrm{CD}_{\mathrm{LM}}$ testi ve Pesaran vd. (2008) tarafindan geliştirilen sapması düzeltilmiş LMadj(Adjusted Lagrange Multiplier) testiyle incelenmiştir. $\mathrm{CD}_{\mathrm{LM} 1}$ ve $\mathrm{CD}_{\mathrm{LM} 2}$ testleri zaman periyodu, birim sayısından 
fazla $(T>N)$ olduğunda uygulanmaktadır. Böylece olası bağımlılığın varlığında değişen varyansın nedeninin de analiz edilmesi sağlanacaktır. Pesaran vd. (2004) $\mathrm{CD}_{\mathrm{LM}}$ testi ise, daha geniş bir ölçekte hem $\mathrm{T}>\mathrm{N}$ hem de $\mathrm{N}>\mathrm{T}$ durumlarında kullanılabilmektedir. Pesaran vd. (2008), paneli oluşturan her bir birimin ortalamalarının sıfirdan farklı olması durumunda kullanılmaktadır. Ortalamaların farklı olmasına bağlı test istatistiğine varyans ve ortalama eklenerek sapması düzeltilmiş test istatistiği (LMadj) elde edilmektedir. Bu test istatistiği de yine her iki durumda kullanılabilmektedir $(\mathrm{T}>\mathrm{N}, \mathrm{N}>\mathrm{T})$.

Tablo 2: Yatay Kesit Bağımlılı̆̆ı Testi Sonuçları

\begin{tabular}{|c|c|c|c|c|c|c|}
\hline & & $3 \mathrm{~A}$ & & $\overline{\mathrm{CA}}$ & & ii \\
\hline & \begin{tabular}{|l|} 
Test İst. \\
\end{tabular} & Olasılık & \begin{tabular}{|l|} 
Test İst. \\
\end{tabular} & Olasılık & \begin{tabular}{|l|} 
Test İst. \\
\end{tabular} & Olasılık \\
\hline LM & 25.581 & 0.004 & 16.972 & 0.075 & 23.258 & 0.010 \\
\hline CDLM & 3.484 & 0.000 & 1.559 & 0.060 & 2.965 & 0.002 \\
\hline CD & -2.018 & 0.022 & -2.154 & 0.016 & 2.269 & 0.012 \\
\hline LMadj & 2.875 & 0.002 & 6.301 & 0.000 & 2.816 & 0.002 \\
\hline
\end{tabular}

Tablo 2'den elde edilen sonuçlara göre $\% 5$ güven düzeyinde temel hipotez reddedilmekte alternatif hipotez kabul edilmektedir. Böylece söz konusu ülkelerde yatay kesit bağımlılığının olduğu sonucuna varılmıştır. Burada çıkan sonuç Kırılgan Beşli ülkelerinin güçlü bir ilişki içerisinde olduğunu ülkelerden birinde meydana gelen bir şokun diğer ülkeleri de etkilediğini ifade etmektedir. Bu nedenle çalı̧̧mada yatay kesit bağımlılığının varlığına bağlı olarak parametrelerin daha etkin tahmini için bu etkiyi dikkate alan testler kullanılmıştır. Çalışmada seçilen ülke grubunun birlikte analize dahil edilmesi gereğini destelemiştir.

\subsection{CADF Panel Birim Kök Testi}

Kırılgan beşli ülkelerinde yatay-kesit bağımlılı̆̆ tespit edildiğinden, değişkenlerin durağanlık özellikleri yatay kesit bağımlığını dikkate alan Pesaran (2007), Yatay Kesit Genelleştirilmiş Dickey-Fuller (CADF), panel birim kök test yöntemleri ile de araştırılmıştır. CADF testinde paneli oluşturan her bir birim için CADF test istatistiği değerleri hesaplanmakta, daha sonra gecikmeli değişkenlerin t-istatistiklerinin basit ortalaması alınarak panelin geneli için CIPS(CrossSectionally Augmented IPS) test istatistiği değerleri bulunmaktadır. Bulunan CADF ve CIPS test istatistik değeri(mutlak değeri alınmış) kritik tablo değerinden(mutlak değeri) büyük olması durumunda, $\mathrm{H}_{0}$ temel hipotez reddedilmekte, $\mathrm{H}_{1}$ alternatif hipotez ise kabul edilmektedir.

Tablo 3'te program dilinde değişkenlerin birinci farkı seçilmiş olup test istatistikleri, kritik tablo değerleriyle birlikte sunulmuştur.

Tablo 3: CADF Panel Birim Kök Testi Sonuçları

\begin{tabular}{|c|c|c|c|c|c|c|c|c|}
\hline \multirow{3}{*}{$\begin{array}{l}\text { Kırılgan } \\
\text { Beşli } \\
\text { Ülkeleri }\end{array}$} & \multicolumn{4}{|c|}{ BA (birinci fark) } & \multicolumn{4}{|c|}{ CA (birinci fark) } \\
\hline & \multicolumn{2}{|l|}{ Sabit } & \multicolumn{2}{|c|}{ Sabit ve Trend } & \multicolumn{2}{|l|}{ Sabit } & \multicolumn{2}{|c|}{ Sabit ve Trend } \\
\hline & Test İst. & Lags & Test İst. & Lags & Test İst. & Lags & Test İst. & Lags \\
\hline Brezilya & -2.789 & 1 & -2.920 & 1 & -2.984 & 1 & -2.788 & 2 \\
\hline Hindistan & $-3.542 * *$ & 1 & $-4.221 * *$ & 1 & -2.573 & 1 & -2.426 & 1 \\
\hline Endonezya & -0.956 & 3 & 0.230 & 3 & -2.255 & 1 & -1.914 & 1 \\
\hline
\end{tabular}


Seher Baş / İkiz Açık Hipotezinin Geçerliliğinin Kırılgan Beşli Ülkeleri İçin Test Edilmesi

\begin{tabular}{|c|c|c|c|c|c|c|c|c|}
\hline $\begin{array}{l}\text { Güney } \\
\text { Afrika }\end{array}$ & -2.400 & 2 & - $3.552 * * *$ & 2 & -2.350 & 1 & -2.229 & 1 \\
\hline Türkiye & -2.288 & 3 & -2.477 & 3 & $-6.104 * *$ & 1 & $-5.700 * *$ & 1 \\
\hline CIPS-stat & \multicolumn{2}{|c|}{$-2.395 * *$} & \multicolumn{2}{|l|}{$-2.588 * * *$} & \multicolumn{2}{|l|}{$-3.253 * *$} & \multicolumn{2}{|l|}{$-3.012 * *$} \\
\hline
\end{tabular}

Not: Maksimum gecikme uzunluğu 3 olarak alınmış ve optimal gecikme uzunlukları, Schwarz bilgi kriterine göre seçilmiş ve 1 olarak tespit edilmiştir. Her ülke için CADF istatistiği kritik değerleri, sabitli modelde -4.35 (\% $\left.1^{*}\right)$, $-3.43\left(\% 5^{* *}\right)$ ve $-3.00(\% 10 * * *)$ sabitli ve trendli modelde $-4.97(\% 1 *),-3.99\left(\% 5^{* *}\right)$ ve $-3.55(\% 10 * * *)$ (Pesaran 2007, tablo I(b ve c) s:275, 276). Panel istatistiği kritik değerleri, sabitli modelde $-2.60(\% 1 *),-2.34\left(\% 5^{* *}\right)$ ve $2.21\left(\% 10^{* * *}\right)$ sabitli ve trendli modelde 3.15(\%1*), -2.88(\%5**), -2.74(\%10***) (Pesaran 2007, tablo II(b ve c), s:280,281) Panel istatistiği, CADF istatistiklerinin ortalamasıdır. (***), $(* *)$ ve $(*)$ simgeleri sırasıyla $\% 1, \% 5$ ve $\% 10$ seviyelerinde anlamlılık düzeylerini göstermektedir.

CADF test sonuçlarına göre ele alınan örneklemdeki ülkelerde tüm değişkenler için durağanlık sağlanamamıştır. Ancak genel panel istatistiğinde \%5 ve \%10 anlamlılık düzeylerinde durağanlık sağlanmıştır.

\subsection{SURADF Panel Birim Kök Testi}

Çalışmada uygulanan diğer bir ikinci nesil panel birim kök testi Breuer vd. (2002) tarafından geliştirilen SURADF testidir. SURADF test istatistik değerleri, kritik tablo değerleri ile kıyaslandığında test istatistik değerleri büyükse $\mathrm{H}_{0}$ temel hipotezi kabul edilmekte ve serinin durağan olmadığına karar verilmektedir. SURADF test istatistiği sonuçları ve kritik değerler (\%5 ve \%10 anlamlılık düzeyi) tablo 4'te sunulmuştur.

Tablo 4: SURADF Panel Birim Kök Testi Sonuçları

\begin{tabular}{|c|c|c|c|c|c|c|c|c|c|}
\hline \multirow{3}{*}{$\begin{array}{c}\text { Kırılgan } \\
\text { Beşli } \\
\text { Ülkeleri }\end{array}$} & \multirow{8}{*}{ 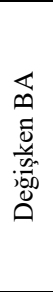 } & \multicolumn{4}{|c|}{ Sabit(birinci fark) } & \multicolumn{4}{|c|}{ Sabit ve Trend(birinci fark) } \\
\hline & & \multirow{2}{*}{$\begin{array}{l}\text { Test } \\
\text { İstatistiği }\end{array}$} & \multirow[t]{2}{*}{ Lags } & \multicolumn{2}{|c|}{ Kritik Değer } & \multirow{2}{*}{$\begin{array}{l}\text { Test } \\
\text { İstatistiği }\end{array}$} & \multirow[t]{2}{*}{ Lags } & \multicolumn{2}{|c|}{ Kritik Değer } \\
\hline & & & & 0.05 & 0.10 & & & 0.05 & 0.10 \\
\hline Brezilya & & -2.269 & 1 & -3.914 & -3.329 & -2.617 & 1 & -5.737 & -4.924 \\
\hline Hindistan & & $-5.861 *$ & 1 & -4.294 & -3.658 & -3.919 & 1 & -6.120 & -5.268 \\
\hline Endonezya & & -1.648 & 3 & -4.586 & -3.921 & -4.339 & 3 & -6.367 & -5.520 \\
\hline Güney Afrika & & -1.906 & 2 & -4.169 & -3.591 & -3.213 & 2 & -5.330 & -4.592 \\
\hline Türkiye & & -3.832 & 3 & -4.787 & -4.120 & -4.906 & 3 & -6.344 & -5.363 \\
\hline \multirow{3}{*}{$\begin{array}{c}\text { Kırılgan } \\
\text { Beşli } \\
\text { Ülkeleri }\end{array}$} & \multirow{8}{*}{ 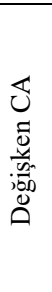 } & \multicolumn{4}{|c|}{ Sabit(birinci fark) } & \multicolumn{4}{|c|}{ Sabit ve Trend(birinci fark) } \\
\hline & & \multirow{2}{*}{$\begin{array}{l}\text { Test } \\
\text { İstatistiği }\end{array}$} & \multirow[t]{2}{*}{ Lags } & \multicolumn{2}{|c|}{ Kritik Değer } & \multirow{2}{*}{$\begin{array}{l}\text { Test } \\
\text { İstatistiği }\end{array}$} & \multirow[t]{2}{*}{ Lags } & \multicolumn{2}{|c|}{ Kritik Değer } \\
\hline & & & & 0.05 & 0.10 & & & 0.05 & 0.10 \\
\hline Brezilya & & -3.540 & 1 & -4.499 & -3.965 & -4.824 & 2 & -5.687 & -4.919 \\
\hline Hindistan & & -2.648 & 1 & -4.353 & -3.755 & -2.580 & 1 & -5.000 & -4.391 \\
\hline Endonezya & & -2.917 & 1 & -4.370 & -3.843 & $-4.812^{*}$ & 1 & -4.885 & -4.295 \\
\hline Güney Afrika & & $-4.440 *$ & 1 & -4.474 & -3.881 & $-4.307 *$ & 1 & -4.763 & -4.155 \\
\hline Türkiye & & $-4.033 *$ & 1 & -4.351 & -3.780 & -4.028 & 1 & -5.621 & -4.963 \\
\hline
\end{tabular}

Not: Kritik değerler 10.000 döngüyle Monte Carlo Simülasyonu'nda hesaplanmıştır. Lag 3 alınmıştır. (**) ve (*) simgeleri sırasıyla $\% 5$ ve $\% 10$ seviyelerinde anlamllık düzeylerini göstermektedir.

SURADF test sonuçları da CADF test sonuçları ile benzerlik göstermiştir. Test sonuçlarına göre $\% 5$ ve $\% 10$ anlamlılık düzeylerinde hem sabit hem de sabit ve trendli modellerde birim kök araştırılmış ve tüm ülkeler için durağanlık sağlanamamıştır. Serilerin durağan olmaması meydana gelen şokların etkisinin kalıcı olduğunu göstermektedir. Eşbütünleşme testi seçiminde serilerin durağan olmama durumlarını dikkate alan testler kullanılmıştır. 


\subsection{Delta Testi}

Bundan sonraki aşama ise, temel hipoteze yönelik katsayı tahminlerinin elde edilmesidir. Katsayı tahminlerine geçmeden önce sabit ve eğim parametrelerinin homojen olup olmadığı Pesaran ve Yamagata (2008) Swamy testi yardımıyla belirlenmiştir. Panel EKK yöntemiyle elde edilen sabit ve eğim parametrelerinin, $\mathrm{H}_{0}$ temel hipotezi homojen olduğu varsayımına dayanırken alternatif hipotez sabit ve eğim parametrelerinin heterojen olduğunu göstermektedir.

Tablo 5: Delta Testi Sonuçları

\begin{tabular}{|l|l|l|}
\hline & Test İstatistiği & Olasılık Değeri \\
\hline$\tilde{\Delta}$ & 4.968 & 0.000 \\
\hline$\tilde{\Delta}_{a d j}$ & 5.414 & 0.000 \\
\hline $\begin{array}{l}\text { Ho: Homejenlik vardir. } \\
\text { H1: Heterojenlik vardir. }\end{array}$ \\
\hline
\end{tabular}

Delta testi sonuçlarına göre, büyük örneklemler için hesaplanan test istatistiği ve küçük örneklemler için düzeltilmiş test istatistikleri sonuçlarına göre temel hipotez reddedilmiş alternatif hipotez kabul edilmiştir. Buna göre eş bütünleşme denkleminde, sabit terim ve eğim katsayılarının heterojen olduğu sonucuna ulaşılmıştır.

\section{Testi}

\subsection{Westerlund Hata Düzeltme Modeli (ECM) Panel Eşbütünleşme}

Birim kök testi sonuçları değişkenlerin durağan olmadığını göstermiştir. Serilerin birim kök içerdiği durumlarda, sistemi etkileyen şoklar kalıcı olabilmektedir. Buna rağmen bu serilerin doğrusal bileşimleri durağan olabilmekte ve seriler arasında uzun dönemde bir denge ilişkisinin varlığı mümkün olabilmektedir(Tatoğlu, 2013:233). Bu nedenle değişkenler arasında koentegre ilişkinin araştırılabilmesi için doğrusal olmayan panel veri modellerinde eş bütünleşme ilişkisini test eden Westerlund(2007) hata düzeltme modeli testi tercih edilmiştir. $\mathrm{Bu}$ testi tercih etme nedenlerimizden bir diğeri serilerde heterojenliğe izin vermesidir. $\mathrm{Bu}$ testte koşullu bir hata düzeltme modelindeki hata düzeltme teriminin sıfıra eşit olup olmadığını test ederek eşbütünleşmenin sıfır hipotezini test etmek için tasarlanmış dört panel eşbütünleşme testi önerilmiştir.

İki test, panelin tümü için alternatif hipotezde eşbütünleşme ilişkisinin varlığını test ederken, diğer ikisi eşbütünleşmiş en az bir birimin var olduğu alternatifini test etmektedir. Asimptotik sonuçlar, testlerin normal dağılımları sınırladığını ve tutarlı olduklarını göstermektedir. İstatistiklerden ikisi panelin yatay kesit boyunca hata düzeltme bilgisine dayanmaktadır. Bunlar panel istatistikleri olarak adlandırılır. Diğer test çifti grup ortalama istatistikleri olarak adlandırılır. Bu ayrımın önemi alternatif hipotezin formülasyonunda yatmaktadır. Panel istatistik için, sıfır hipotezi ve alternatif hipotez $\mathrm{H}_{0}: \alpha_{\mathrm{i}}=0, \mathrm{H}^{\mathrm{p}_{1}}: \alpha_{\mathrm{i}}<0$ tüm i'ler için kurulmaktadır. $\mathrm{H}_{0}$ 'ın reddedilmesi panelin tümü için eşbütünleşme ilişkisinin kanıtıdır. Aksine, grup istatistik için, $\mathrm{H}_{0}: \alpha_{\mathrm{i}}=0, \mathrm{H}_{1}^{\mathrm{g}}{ }_{1}: \alpha_{\mathrm{i}}<0$ en az bir birim için, $\mathrm{H}_{0}$ 'ın reddi yatay kesit birimlerinden en az biri için eşbütünleşme kanıtı olarak 
alınmıştır (Westerlund, 2007:710-712). Model açıklamalarında Joakim Westerlund (2007) makalesinden yararlanmıştır.

Grup ortalama istatistiklerinin oluşturulması üç adımda gerçekleştirilmektedir. $\Delta y i t=\delta^{\prime} i d t+\alpha i y i j-1+\lambda^{\prime} i x i t-1+\sum_{j=1}^{p i} a i j \Delta y i j-j+\sum_{j=0}^{p i} \gamma i j \Delta x i t-j+e i t$.

İlk adım, denklem (1) her $i$ için en küçük kareler ile tahmin edilmektedir.

$\Delta y i t=\hat{\delta}^{\prime} i d t+\widehat{\alpha} i y i j-1+\hat{\lambda}^{\prime} i x i t-1+\sum_{j=1}^{p i} \hat{a} i j \Delta y i j-j+\sum_{j=0}^{p i} \hat{\gamma} i j \Delta x i t-j+\hat{e} i t$.

İkinci adımda $\alpha_{i}^{\prime}$ yi tahminleyerek $\hat{\alpha}_{\mathrm{i}}$ elde ederiz

$$
\alpha i(1)=1-\sum_{j=1}^{p i} \alpha i j \quad \text { denklem } \quad \tilde{\alpha} i(1)=1-\sum_{j=1}^{p i} \hat{a} i j
$$

Üçüncü adım, test istatistiklerini aşağıdaki gibi hesaplamaktır.

$\mathrm{G} t=\frac{1}{N} \sum_{i=1}^{N} \frac{\alpha i}{\operatorname{SE}(\alpha i)}$ ve $\mathrm{G} \alpha=\frac{1}{N} \sum_{i=1}^{N} \frac{\widehat{\alpha} i}{\alpha i(1)}$.

$\operatorname{SE}\left(\widehat{\alpha}_{\mathrm{i}}\right), \widehat{\alpha}_{\mathrm{i}}^{\prime}$ 'nin standart hatasidır.

Westerlund panel istatistiklerinin, denklemin (1) hem parametrelerinin hem de boyutunun kesit birimleri arasında farkl1lı göstermesine izin verilmesi nedeniyle karmaşık olduğunu ve bu nedenle bu testleri uygulamak için üç aşamalı bir prosedür önermektedir.

Panel istatistikte birinci adım, grup ortalama istatistikleriyle aynıdır ve pi'nin, gecikme sırasının belirlenmesini içerir.

$\Delta \tilde{y} i t=\Delta y i t-\hat{\delta}^{\prime} i d t+\hat{\lambda}^{\prime} i x i t-1+\sum_{j=1}^{p i} \hat{a} i j \Delta y i j-j+\sum_{j=0}^{p i} \hat{\gamma} i j \Delta x i t-j$,
$\tilde{y} i t-1=y i t-1-\tilde{\delta}^{\prime} i d t+\tilde{\lambda}^{\prime} i x i t-1+\sum_{j=1}^{p i} \tilde{a} i j \Delta y i j-j+\sum_{j=0}^{p i} \tilde{\gamma} i j \Delta x i t-j$,

İkinci adım, ortak hata düzeltme parametresini $(a)$ ve onun standart hatasını tahmin etmek için $\Delta \tilde{y}_{\text {it }}$ ve $\tilde{y}_{\text {it }-1}$ kullanmayı içerir. Özellikle,

$$
\begin{gathered}
\hat{a}=\left(\sum_{i=1}^{N} \sum_{t=2}^{T} \tilde{y}^{2} i t-1\right)-1 \sum_{i=1}^{N} \sum_{t=2}^{T} \frac{1}{\hat{a} i(1)} \tilde{y} i t-1 \Delta \tilde{y} i t . \\
\operatorname{SE}(\hat{\alpha})=\left(\left(\hat{S}_{N}^{2}\right)^{-1} \sum_{i=1}^{N} \sum_{t=2}^{T} \tilde{y}^{2} i t-1\right)^{-1 / 2} \\
\hat{S}_{N}^{2}=\frac{1}{N} \sum_{i=1}^{N} \hat{S}_{i}^{2} .
\end{gathered}
$$

Üçüncü adımda panel istatistik hesaplanmaktadır.

$$
P_{t=\frac{\hat{a}}{\operatorname{SE}(\hat{a})}} \text { ve } P_{\alpha=T \widehat{\alpha}}
$$


Tablo 6: Westerlund Hata Düzeltme Modeli Panel Eşbütünleşme Testi Sonuçları

\begin{tabular}{|c|c|c|c|}
\hline Test & İstatistik & $\begin{array}{c}\text { Asimtotik } \\
\text { Olasılık } \\
\text { Değeri }\end{array}$ & $\begin{array}{c}\text { Bootstrap } \\
\text { Olasılık } \\
\text { Değeri }\end{array}$ \\
\hline Gt & -3.437 & -3.009 & 0.001 \\
\hline Ga & -13.623 & -0.580 & 0.281 \\
\hline $\mathbf{P t}$ & -6.724 & -2.329 & 0.010 \\
\hline $\mathbf{P a}$ & -14.909 & -2.229 & 0.013 \\
\hline \multicolumn{3}{|c|}{$H_{0}:$ Eşbütünleşme ilişkisi yoktur. } \\
\hline \multicolumn{3}{|c|}{$H_{1}:$ Eşbütünleşme ilişkisi vardır. } \\
\hline
\end{tabular}

Not:Bootstrap olasılık değerleri 10.000 tekrarlı dağılımdan elde edilmiştir.

$\mathrm{Ga}$ dışındaki istatistiklere göre $\mathrm{H}_{0}$ hipotezi red edilmiştir. Bütçe açığ cari açık arasında uzun dönemli bir ilişki bulunmaktadır. Eşbütünleşme ilişkisinin varlığı serilerin uzun dönemde birlikte hareket ettiğini göstermiştir. Bu sonuçlar kısa ve uzun dönemli ilişkiyi ve bu ilişkinin yönünün tahminlenmesi için parametre tespitine ilişkin testlere yönlendirmiştir.

\subsection{Kısa ve Uzun Dönemli İlişkilerin Tahmini}

Değişkenler arasında uzun dönemli ilişkinin varlığı ispatlandıktan sonra hem kısa ve uzun dönemli ilişki hem de bu ilişkinin yönü Havuzlanmış Ortalama Grup Tahmincisi(PMGE), Ortalama Grup Tahmincisi(MGE) ve Dinamik Sabit Etkiler Tahmincisi gibi yöntemler kullanılarak belirlenmektedir. Tahminciler arasında seçim yapmak için Hausman Testi kullanılabilmektedir. Hausman testi sonuçlarına göre, Havuzlanmış Ortalama Grup Tahmincisi tercih edilmiştir. Buna göre uzun dönem parametrelerinin birimden birime değişmediği homojen olduğu sonucuna ulaşılmıştır. Tablo 7'de PMGE ve Hausman testi sonuçlarına yer verilmiştir.

Tablo 7: Havuzlanmıș ortalama grup tahmincisi(PMGE)

\begin{tabular}{|l|l|l|l|}
\hline Değişkenler & Katsayı & Std. Hata & İstatistik \\
\hline $\mathrm{Ca}($ Uzun dönem) & $0.3479728^{* * *}$ & .1457364 & 0.017 \\
\hline $\mathrm{ec}$ & $-0.2754982^{* * *}$ & .0599352 & 0.000 \\
\hline $\mathrm{Ca}($ Kisa dönem) & $-0.3921026 * * *$ & .0818746 & 0.000 \\
\hline Hausman testi & $0.21(0.6453)$ & \\
\hline
\end{tabular}

Not: $(* * *),(* *)$ ve $(*)$ simgeleri sırasıyla $\% 1, \% 5$ ve $\% 10$ seviyelerinde anlamlılık düzeylerini göstermektedir.

Tablo 7'deki PMGE sonuçları, kırılgan beşli ülkelerinin geneli için bütçe açığı ve cari açık arasında kısa ve uzun dönemli ilişki hakkında bilgi vermektedir. Hata düzeltme parametresi(ec), serilerin durağan olmamasından kaynaklanan kısa dönem sapmaların bir sonraki dönemde dengeye gelme hızını ve iki değişken arasında uzun dönemli bir ilişki olduğunu göstermektedir. Buna göre bir dönemde meydana gelen dengesizliklerin \%27'si bir sonraki dönemde düzelmekte ve uzun dönem dengesine yaklaşmasını sağlamaktadır. Bütçe açığının uzun dönem parametresi (0.34) anlamlı ve pozitif işaretlidir. K1sa dönem parametresi $(-0,39)$ istatistiksel olarak anlamlıdır. Uzun dönemde bütçe açığı ile cari açık arasında pozitif ilişki varken, kısa dönemde ilişkinin yönü negatif olmaktadır. Uzun dönemde bütçe açığındaki \% 1'lik artış, cari açığ1 \% 0.34 oranında arttırmaktadır. 
Tablo 8: Birimler İçin Havuzlanmıș Ortalama Grup Tahmincisi

\begin{tabular}{|l|l|l|l|l|}
\hline Kırılgan Beşli & Değişkenler & Katsayı & Std. Hata & İstatistik \\
\hline \multirow{3}{*}{ Brezilya } & $\mathrm{ec}$ & $-0.3177912^{* *}$ & 0.1652961 & 0.055 \\
\cline { 2 - 5 } & $\mathrm{Ca}$ (Kısa dönem) & -0.3737535 & 0.3178629 & 0.240 \\
\hline \multirow{3}{*}{ Hindistan } & $\mathrm{ec}$ & $-0.2730428^{*}$ & 0.1739234 & 0.116 \\
\cline { 2 - 5 } & $\mathrm{Ca}$ (Kısa dönem) & -0.2226264 & 0.2827043 & 0.431 \\
\hline \multirow{3}{*}{ Günney Afrika } & $\mathrm{ec}$ & $-0.4607173^{* * *}$ & 0.1745231 & 0.008 \\
\cline { 2 - 5 } & $\mathrm{Ca}($ Kisa dönem) & $-0.2189023^{*}$ & 0.1297524 & 0.092 \\
\cline { 2 - 5 } & $\mathrm{ec}($ Kisa dönem) & $-0.2351448^{* *}$ & 0.1195342 & 0.049 \\
\hline \multirow{2}{*}{ Türkiye } & $\mathrm{ec}$ & $-0.5024651^{* * *}$ & 0.1938643 & 0.010 \\
\cline { 2 - 5 } & $\mathrm{Ca}($ Kısa dönem) & -0.0907949 & 0.077159 & 0.239 \\
\hline \multirow{2}{*}{} & & $-0.6427654 * * *$ & 0.1307229 & 0.000 \\
\hline
\end{tabular}

Not: $(* * *),(* *)$ ve $(*)$ simgeleri sirasılyla $\% 1, \% 5$ ve $\% 10$ seviyelerinde anlamlllı düzeylerini göstermektedir.

Tablo 8'de cari açık ile bütçe açığı arasında her ülke için kısa dönemli ilişki ve hata parametreleri gösterilmektedir. Sonuçlara göre, Türkiye dışındaki ülkelerin kısa dönem hata düzeltme parametreleri anlamlı ve negatiftir, dolayısıyla bu ülkelerde cari açık ile bütçe açığı değişkenleri arasında kısa dönemli bir ilişki vardır. Kısa dönemde Brezilya' da bütçe açığında meydana gelen \%1'lik artış, cari açığı \%37, Hindistan'da \%22, Endonezya'da \%21 ve Güney Afrika'da \%50 azaltmaktadır.

\section{SONUÇ}

İkiz açık ülke ekonomilerinin performansına ilişkin önemli göstergelerden biri olarak kabul edilir. Cari açık ve bütçe açığının büyüklüğü ve ekonomideki yansımaları ekonomi politikalarını yönlendiren önemli sorunlara neden olabilmektedir. Özellikle sermaye bakımdan dışarıya bağlı olan ve büyümesini de büyük oranda dış kaynaklarla sağlayan ülkeler açısından cari açık ve bütçe açığı daha büyük önem teşkil edecektir. Bu bakımdan ikiz açık ekonomik kararların oluşma sürecinde önemli bir rol oynar.

$\mathrm{Bu}$ çalışmada öncelikle literatürde yer alan ikiz açık hipotezlerine yönelik kuramsal yaklaşımlar değerlendirilmiş ve farklı ülkeler üzerine yapılmış ampirik çalışmalardan elde edilen sonuçların geniş bir özeti sunulmuştur. Daha sonra çalışmada kullanılacak veri seti ve izlenecek yöntem ele alınmıştır. Son olarak ampirik analiz sonucunda elde edilen bulgular açıklanmış ve değerlendirilmiştir.

Çalışmanın sonuçları, bütçe açıklarının cari açıklara yol açacağını ileri süren Geleneksel Keynesyen Yaklaşımı desteklemektedir. Elde edilen sonuçlara göre, bütçe açığında meydana gelen bir artış cari açıkta artışa neden olmaktadır. Çalışmamızın bulguları literatürde bir takım yerli ve yabancı çalışmaların sonuçlarıly paralellik göstermektedir. ${ }^{1}$

Çalışmanın çıktıları ele alındığında cari açık ile bütçe açığı arasındaki ilişkinin varlığı kanıtlarla ortaya konmaktadır. Analize ilk olarak yatay kesit bağımlılığının değerlendirilmesi ile başlanmıştır. Elde edilen sonuçlar Kırılgan Beşli ülkelerinde yatay kesit bağımlılı̆̆ının olduğunu göstermiştir. Buna göre bu ülkelerde ekonomiyi etki altına alan bir olaydan diğer ülkelerinde etkilendiği dolayısıyla birlikte hareket ettiklerini göstermiştir. Bu sonuç ülke grubunun panel

${ }^{1}$ (Rosenweing ve Tallman, 1993; Salvatore, 2006; Acaravci ve Öztürk, 2008; Aydın ve Afsal, 2018) 
veri analizi yöntemleri ile birlikte değerlendirilmesi gerektiği görüşünü desteklemiştir. Sabit ve eğim parametrelerinin homojenliği Pesaran ve Yamagata (2008) tarafından geliştirilen Swamy testi yardımıyla belirlenmiştir. Buna göre eş bütünleşme denkleminde, sabit terim ve eğim katsayılarının heterojen olduğu sonucuna ulaşılmıştır. Bu yüzden sonuçlar hem katsayı heterojenliğini dikkate alan hem de yatay kesit bağımlılığını dikkate alan birim kök testlerini kullanmaya yönlendirmiştir. SURADF ve CADF olmak üzere iki birim kök testi uygulanmıştır. İki testin sonuçları benzerlik göstererek tüm ülkeler ve değişkenler için durağanlık sağlanamamıştır. $\mathrm{Bu}$ nedenle birim kökü dikkate alan Westerlund Hata düzeltme Modeli Panel Eşbütünleşme testi kullanılmıştır. Sonuçlar beklendiği gibi cari açık ve bütçe açığının birlikte hareket ettiğini göstermiştir. Son aşamada ise, cari açık ve bütçe açığının kısa ve uzun dönemde nasıl ve ne yönde hareket ettiği ise, Havuzlanmış Ortalama Grup-Birim tahmincisi ile ortaya konulmuştur. Sonuçlara göre, hata düzeltme parametresi -0.27 negatif işaretli ve istatistik değerleri anlamlı bulunmuştur. Bütçe açığının uzun dönem parametresi 0.34 anlamlı ve pozitif işaretlidir. Kısa dönem parametresi -0.39 istatistiksel olarak anlamlıdır. Uzun dönemde bütçe açığı ile cari açık arasında pozitif ilişki varken, kısa dönemde ilişkinin yönü negatif olmaktadır. Uzun dönemde bütçe açığındaki \% 1'lik artış, cari açığ $1 \% 0.34$ oranında arttırmaktadır. Her bir Kırılgan Beşli ülkesi tek tek incelendiğinde ise, kısa dönemde Brezilya' da bütçe açı̆̆ında meydana gelen \%1'lik artış, cari açığı \%37, Hindistan'da \%22, Endonezya'da \%21 ve Güney Afrika'da $\% 50$ azaltmaktadır. Çalışma bulguları uzun vadede Keynesyen Yaklaşımı desteklemektedir. Ekonomi politikaları bazında bakıldığında, tercih edilen politikaların bütçe dengelerini bozmayacak şekilde ve dış açıkları giderecek biçimde birbirleriyle uyumlu olmasına dikkat edilmesi gerekir. Diğer taraftan çalışmanın, kırılgan beşli olarak kabul edilen ülkelerdeki cari açık seviyelerinin politika belirleyicilerin harcamaları ve bütçelerini biçimlendirmelerine ve kaynaklarını daha etkin tahsis etmelerine yardımcı olacağı düşünülmektedir.

\section{KAYNAKÇA}

Acaravci, A., \& Öztürk, I. (2008). Twin deficits phenomenon: Empirical evidence from the ARDL bound test approach for Turkey. Bulletin of Statistics and Economics, 2(A08), 57-64.

Altunöz, U. (2014). İkiz Açık Hipotezinin Geçerliliğinin Sınır Yöntemiyle Sınanması: Türkiye Örneği. Adıyaman Üniversitesi Sosyal Bilimler Enstitüsü Dergisi, (17), 425-446.

Aydın, B., \& Afsal, M. Ş. (2018). Türkiye'de İkiz Açık Hipotezi: Toda-Yamamoto Nedensellik Yaklaşımı. Uluslararası Ekonomi İșletme ve Politika Dergisi, 2(2), 231-240.

Bakarr, T. A. (2014). Fiscal Deficits and Current Account Imbalances: Evidence from Sierra Leone, International Journal of Business and Social Sciences, 5 (8/1), 256-269.

Barro, R. J., (1989). The Ricardian Approach to Budget Deficits. Journal of Economic Perspectives, $3(2), 37-54$.

Bayrak, M., \& Esen. Ö. (2012). Bütçe açıklarının cari işlemler dengesi üzerine etkileri: İkiz açıklar hipotezinin Türkiye açısından değerlendirilmesi. Ekonomik Yaklaşım, 23(82), 23-49.

Chang, J. C., \& Hsu, Z. (2009). Causality relationships between the twin deficits in the regional economy. Department of Economics, National Chi Nan University, (04/06). 
Corsetti, G. \& Müller, G. J. (2006). Twin Deficits: Squaring Theory, Evidence and Common Sense, Economic Policy, 21 (48): 597-638.

Çavdar, Ş. Ç. (2011). Türkiye İçin İkiz Açık Hipotezinin Testi, e-Journal of New World Sicences Academy - Social Sciences, 6 (4), 422-431.

Çelik, S., Deniz, P. ve Eken, S. (2008). Eşbütünleşme Analiziyle Altı Gelişmekte Olan Ülke için İkiz Açıklar Hipotezi, 2. Ulusal İktisat Kongresi (20-22 Şubat 2008) Dokuz Eylül Üniversitesi İIBF İktisat Bölümü, İzmir.

Darrat, A. F. (1988). Have large budget deficits caused rising trade deficits?. Southern Economic Journal, 54(4), 879-887.

Erceg, C. J., Guerrierı, L., \& Gust, C. (2005). Expansionary Fiscal Shocks and the US Trade Deficit, International Finance, 8(3), 363-397.

Garcia, A. \& J. Ramajo (2004). Budget Deficit and Interest Rates: Empirical Evidence for Spain, Applied Economics Letters, 11(11). 715-18.

İyidoğan, V. P. (2013). The Twin Deficits Phenomenon in Turkey: An Empirical Investigation, Journal of Business, Economics \& Finance, 2 (3), 36-42.

İyidoğan, P. V. (2014). The Analysis of the Causal Relationship Between Budget Balance and Current Account Balance by MGARCH Methodology: Turkey Experience. Anadolu Üniversitesi Sosyal Bilimler Dergisi, 14(2). 71-80.

İyidoğan, V. P. \& Erkam, S. (2013). İkiz Açıklar Hipotezi: Türkiye İçin Ampirik Bir İnceleme (19872005), Pamukkale Üniversitesi Sosyal Bilimler Enstitüsü Dergisi, 15, 39-48

J. A. Hausman, Specification Tests in Econometrics, Econometrica, Volüm: 46, No: 6 , November 1978, 1251-1271.

Kalou, S. \& Paleologou, S. M. (2012). The Twin Deficits Hypothesis: Revisiting an EMU Country, Journal of Policy Modelling, 34, 230-241.

Kaygısız, A. D., Kaya. D. G., \& Kösekahyaoğlu, L. (2016). Test Of 'Twin Deficit Hypothesis'for Turkey: An Analysis for 2001-2014 Period. Ömer Halisdemir Üniversitesi İktisadi ve İdari Bilimler Fakültesi Dergisi, 9(4), 211-228.

Kearney, C., \& Monadjemi, M. (1990). Fiscal policy and current account performance: International evidence on the twin deficits. Journal of Macroeconomics, 12(2), 197-219.

Kim, C. H., \& Kim, D., (2006). Does Korea have twin deficits?. Applied Economics Letters, 13(10), 675-680.

Özçalık, M. Ve Erataş, F. (2014). İkiz Açılar Hipotezinin Geçerliliği: Yükselen Piyasa Ekonomileri İçin Bir Örnek. Yönetim ve Ekonomi Araştırmaları Dergisi. Sayı. 22

Pesaran, H., Smith, Y. ve Shin, R. (2004). Pooled Mean Group Estimation Of Dynamic Heterogeneous Panels, Journal of the American Statistical Association 94(446).

Pesaran, M.H. (2004). General Diagnostic Tests for Cross Section Dependence in Panels. Cambridge Working Papers in Economics, No:435.

Pesaran, M.H.,(2007). A Simple Panel Unit Root Test In The Presence of Cross-Section Dependence, J. Appl. Econ. 22: 265-312.

Pesaran, M.H. ve Yamagata, T. (2008). Testing Slope Homogeneity in Large Panels. Journal of Econometrics, 142(1):50-93.

Pesaran, M.H., Ullah, A. ve Yamagata, T. (2008). A Bias-Adjusted LM Test of Error Cross-Section Independence. Econometrics Journal, 11(1):105-127.

Piersanti, G. (2000). Current account dynamics and expected future budget deficits: some international evidence. Journal of international Money and Finance, 19(2), 255-271.

Rosenswerg, Jeffrey A., \& Tallman, Ellis W. (1993). Fiscal Policy And Trade Adjustment: Are The Deficits Really Twins?, Economic Inquiry, 31(4), 580-594.

Salvatore, D. (2006). Twin Deficits in The G-7 Countries and Global Structural Imbalances. Journal of Policy Modeling, 28(6), 701-712.

Sever, E., \& Demir, M. (2007). Türkiye'de bütçe açı̆̆ı ile cari açık arasındaki ilişkilerin VAR analizi ile incelenmesi. Eskişehir Osmangazi Üniversitesi İİBF Dergisi, 2(1), 47-63.

Summers, L. H. (1988). Tax policy and international competitiveness. In International aspects of fiscal policies, University of Chicago Press. 349-386.

Tatoğlu, Y. F. (2013), İleri Panel Veri Analizi, İstanbul. 
Uğur, A. A., \& Karatay, P. (2009). İkiz Açıklar Hipotezi: Teorik Çerçeve ve Hipoteze Yönelik Yaklaşımlar. Sosyo-Ekonomi, 5(9). 102-122.

Van Bon, N. (2014). Current Account and Fiscal Deficits-Evidence of Twin Divergence from Selected Developing Economies of Asia. Southeast Asian journal of economics, 2(2), 33-48.

Westerlund, Joakim (2007), Testing for Error Correction in Panel Data, Oxford Bulletın of Economics and Statistics, 69, 6 0305-9049.

\section{SUMMARY}

The twin deficit, which expresses the situation where the current account deficit and budget deficit are observed, poses an important problem for both developed and developing economies. Foreign currency deficit arises from the foreign exchange income/expense balance as a result of the transfer of goods, services and capital with other countries, has negative results depending on the financing method. Financing current account deficit through short-term speculative flows increases the vulnerability in developing country. Likewise, if the requirement for foreign currency to balance the current account deficit causes borrowing deficiency for public finance, it will create a burden on the budget in the long term.) The method of financing budget deficit will increase the indebtedness levels of countries, especially of interest rates. For these reasons, the emergence of twin deficit causes more fragile economies.

The literature examining the twin deficits is handled within the framework of four different theoretical approaches. These are as follows; Traditional or Keynesian Approach, Ricardian Equivalence Approach, Monetarist Approach and Current Account Targeting Approach. When empirical studies are analyzed, it is observed that the data of budget deficit and current account deficit in different countries are tested by different methods. Although consensus has not been achieved yet, the twin deficit still continues to be a problem for many economies. Particularly, the fragile five countries (Brazil, Indonesia, South Africa, India and Turkey), which have been on the agenda with their economic weaknesses, are experiencing high current account deficit, budget deficit and foreign indebtedness due to international capital flows.

In the study, the validity of the twin deficit hypothesis was investigated for Fragile Five (Brazil, Indonesia, South Africa, India and Turkey). In the analysis, annual data for the period of 2000-2017 is taken, panel data methods were used. In this framework, first the cross-sectional dependence is evaluated. Horizontal crosssection dependence; Berusch-Pagan (1980) CDLM1, Pesaran et al. (2004) CDLM2, Pesaran et al. (2004) CDLM test and Pesaran et al. (2008) was examined by the deviation corrected LMadj test (Adjusted Lagrange Multiplier). The results showed that there is a horizontal cross-section dependency in Fragile Five countries. Accordingly, an event that affects one of these countries, would affect the other ones as well, this shows that they are acting together.) The homogeneity of the constant and slope parameters was determined with the help of the Swamy test developed by Pesaran and Yamagata (2008). Accordingly, it is concluded that the constant term and slope coefficients are heterogeneous in the cointegration equation. Therefore, the results are directed to use unit root tests that take account 
both the coefficient heterogeneity and the horizontal cross-section dependency into account. Two unit root tests were applied, SURADF and CADF. The results of the two tests were similar, and stagnation was not achieved for all countries and variables. For this reason, Westerlund Error Correction Model Panel Cointegration test was used, which takes unit root into consideration. The results showed that, as expected, the current account deficit and budget deficit acted together. In the last stage, how and in which directions the current account deficit and budget deficit are moving in the short and long term are demonstrated by the Pooled Average Group-Unit estimator. According to the results, the error correction parameter was found -0.27 negative and statistical values were found significant. The long-term parameter of the budget deficit is 0.34 meaningful and positive. The short run parameter -0.39 is statistically significant. While there is a positive relationship between the budget deficit and the current deficit in the long term, the direction of the relationship is negative in the short term. In the long run, $1 \%$ increase in budget deficit increases current account deficit by $0.34 \%$. When each Fragile Five Country is examined one by one, the $1 \%$ increase in the budget deficit in Brazil in the short term reduces the current account deficit by $37 \%, 22 \%$ in India, $21 \%$ in Indonesia and $50 \%$ in South Africa. The study findings support the Traditional Keynesian Approach, which suggests that budget deficits will lead to current deficits. 